\title{
Effect of mowing on productivity in the endangered Aquatic Warbler Acrocephalus paludicola
}

\author{
JUSTYNA KUBACKA, STEFFEN OPPEL, ANDRZEJ DYRCZ, LARS LACHMANN, \\ J. PEDRO DUARTE BARROS DA COSTA, ULLA KAIL and WANDA ZDUNEK
}

\section{Summary}

The Aquatic Warbler Acrocephalus paludicola is a globally threatened habitat specialist that breeds in open fens in Central and Eastern Europe. Because bush and reed encroachment threaten many suitable breeding areas, habitat management is necessary to maintain the open wetlands that Aquatic Warblers require for nesting. The effectiveness of mowing as habitat management has so far only been assessed by counting the number of singing males. To assess whether mowing also affected vital reproduction parameters, we analysed Aquatic Warbler productivity in the Biebrza National Park, Poland, on plots in four different successional stages after mowing. Our study showed that productivity was lowest in the first year after mowing, but increased to the highest levels in the second year after mowing. The productivity differences between areas at different stages after mowing resulted from differences in nest density, since we found little evidence for an effect of mowing on nest survival or the number of fledglings produced per successful nest. Nest survival was highly variable between years and varied mostly with nest age and nest initiation date. The density of singing males was positively correlated with both the nest density and the number of fledglings produced in an area, suggesting that this simple indicator could be used to rank the quality of Aquatic Warbler habitats. We recommend that in mesotrophic fen mires, such as the Biebrza valley, mowing as habitat management is applied less frequently than every second year.

\section{Introduction}

The Aquatic Warbler Acrocephalus paludicola is a globally threatened oscine species, with a world population estimated at 10,200-14,200 singing males as of 2001-2007 (Flade and Lachmann 2008). Once widespread, it became extinct in Western Europe during the 2oth century and has declined dramatically in Central Europe, which today holds all of its population (BirdLife International 2012). The major reason for this decline has been loss of breeding habitat (Aquatic Warbler Conservation Team 1999, Kozulin and Flade 1999, Kozulin et al. 2004, Flade and Lachmann 2008). The Aquatic Warbler is a habitat specialist, breeding in broad lowland river valleys, mainly on mesotrophic and slightly eutrophic sedge fen mires, with water depth $1-10 \mathrm{~cm}$. Most of its habitats are semi-natural and for many centuries relied solely on traditional, extensive agricultural practices (Kozulin and Flade 1999, Flade and Lachmann 2008). The major threats to its breeding habitat used to be drainage and intensification of agricultural use; however, today the main threat is abandonment of land use and eutrophication (Flade and Lachmann 2008). Discontinued land use can lead to expansion of reeds and shrubs, which has been observed to be negatively associated with the number of singing males occupying an area (Kloskowski and 
Krogulec 1999, Tanneberger et al. 2008, Tanneberger et al. 2010), and eventually leads to complete abandonment of the site by Aquatic Warblers (Kloskowski and Krogulec 1999, Kozulin and Flade 1999, Flade and Lachmann 2008). Proper habitat management is therefore of central importance for the conservation of the Aquatic Warbler.

One of the key habitat management measures applied to maintain Aquatic Warbler habitat is mowing (Flade and Lachmann 2008, Tanneberger et al. 2009), which reduces bush encroachment and tree growth, and limits vegetation height. Guidelines for Aquatic Warbler habitat management have been formulated on the basis of studies correlating habitat features to the number of singing males, which is a commonly used indicator of population size in this species. Although there is evidence that mowing results in an increase in the number of singing males recorded on regularly mown areas, there is currently no information on whether mowing actually increases key demographic parameters, such as productivity. In the Aquatic Warbler, relationships between habitat management and productivity may differ from relationships between management and the number of singing males, because only females construct nests, incubate eggs, and raise young (Schulze-Hagen 1991, Schulze-Hagen et al. 1999). The number of singing males in an area is an indicator of Aquatic Warbler abundance that can be obtained with relatively little effort, but to ensure that it can effectively reflect the vital properties of the population, it needs to be ascertained whether male abundance is positively related to the overall population productivity of an area.

In our study we investigated whether the number of Aquatic Warbler fledglings produced in an area (hereafter referred to as 'area productivity') was related to habitat management, represented by four different successional stages after mowing. Area productivity is of vital interest for land managers but is a composite metric of three ecological mechanisms: nest density, nest survival, and fledged brood size per successful nest. We therefore examined these three components of area productivity independently to investigate which of them was mostly affected by mowing. We then assessed whether our empirical estimates of area productivity and nest density were positively correlated with the number of singing males counted in the same area, to evaluate whether surveys of singing males can be used as an effective indicator of the quality of Aquatic Warbler habitat.

\section{Methods}

\section{Species and study area}

The Aquatic Warbler breeds mainly in open fen mires with sedge vegetation and generally wet ground (Flade and Lachmann 2008). The breeding season lasts from May to August, during which females can raise two broods. The first nest initiation peak occurs in the second half of May, and the second nest initiation peak typically occurs at the end of June (Dyrcz and Zdunek 1993a). Males advertise throughout the whole reproductive season (Dyrcz and Zdunek 1993a), between early May and late July, and do not take part in parental care (Schulze-Hagen et al. 1999). Females build nests on the ground under dry sedges. They are very cryptic and can mainly be detected by alarm calls or when feeding young. Clutch size is $3-6$, most often five, eggs. Incubation lasts 14-16 days, nestling phase is about 14 days and fledglings become independent about 19-23 days after leaving the nest. Females feeding nestlings usually search for food within $30 \mathrm{~m}(5-60 \mathrm{~m})$ distance from the nest and their foraging grounds do not overlap much with foraging grounds of neighbouring females (Wawrzyniak and Sohns 1977, Dyrcz and Zdunek 1993a, 1993b, Aquatic Warbler Conservation Team 1999).

The study was conducted between mid-May and the end of August each year from 2010 to 2012 , at Bagno Eawki, located in the southern basin of the Biebrza National Park, Poland $\left(53^{\circ} 16^{\prime} \mathrm{N}\right.$, $\left.22^{\circ} 33^{\prime} \mathrm{E}\right)$. The Biebrza National Park hosts one of the largest stable populations of the Aquatic Warbler (c.4,000 singing males in 2011, J. Kloskowski, unpubl. report). Bagno Ławki is an extensive semi-natural sedge fen mire, situated in the non-flooded zone of the Biebrza valley, $4-8 \mathrm{~km}$ 
from the Biebrza river. The large size (c.6,500 ha) of this area makes it particularly suitable for a landscape-scale study of habitat management effects on Aquatic Warblers. The fen mires in the Biebrza valley used to be hand-cut for hay for several centuries but farming practices ceased in the 1970s, which caused succession of reeds Phragmites australis and willow Salix spp. shrubs. Since 1993, when the national park was established, Bagno Eawki has been protected and managed for habitat conservation. The main management practice is mowing, currently performed every second year between August and February.

In 2010 the study was conducted on two 20-ha plots, in 2011 on five 20-ha plots and in 2012 on 12 10-ha plots grouped into three blocks. All plots were representative of Aquatic Warbler habitat. We differentiated between four different successional stages of fen mire after mowing: (I) mown in the autumn and/or winter just prior to the current breeding season (hereafter referred to as 'mown +1 year'); (2) mown in the autumn and/or winter one year before the current breeding season ('mown +2 years'); (3) mown in the autumn and/or winter two years before the current breeding season ('mown +3 years'); and (4) not mown for at least 1o years ('unmown'). In our study, the unmown areas, although being at the most advanced succession stage of all treatments, had only slightly higher abundance of bushes than areas mown two or three years earlier. Hence, the unmown areas were still open fen mires and provided suitable habitat for Aquatic Warblers, which however can be lost due to succession if not mown.

Not all of the mowing treatments were represented in each study year. All three years included unmown and mown +1 year plots, while mown +2 years plots were included only in 2011-2012 and mown +3 years areas were included only in 2012. In 2010-2011, four plots contained two of the mowing regimes, and one plot contained all three mowing regimes. In 2012 the 12 plots represented one mowing regime each. Hence, there were in total 23 sampling units with homogeneous management and environmental structure within each unit, ranging in size from 5.6 to to ha. This design was chosen to avoid other environmental factors confounding the effects of mowing. All study plots were located in a large sedge fen mire and not adjacent to other habitat types that may have affected the presence or productivity of Aquatic Warblers within study plots.

\section{Nest search and monitoring}

To find nests, observers searched for alarming or disturbed females, which could be expected to have a nest within the plot. A given plot was searched every $2-4$ days, for $2-5$ hours on each occasion, by $1-3$ people simultaneously. All searchers swapped between plots and parts of a plot in order to minimise bias due to the skill or experience of an observer. All treatment units received equal search effort, i.e. they were searched for alarming females at similar walking speed. Nests were located by observing alarming females at a distance of 20-60 m and by carefully parting vegetation at the spot where the female was seen to land either for incubation or to feed her young. Once a nest was found, its location was marked in the field and recorded with a GPS. The number of eggs or chicks as well as the age of chicks were recorded (following Wawrzyniak and Sohns 1977). For each newly found nest we recorded three habitat measurements that have been found to influence habitat selection in Aquatic Warblers (Tanneberger et al. 2010): water depth, height of the tallest vegetation and thickness of litter layer. Nest search was avoided during prolonged and/or heavy rain, low temperatures and/or strong wind.

Nests were checked every $3-4$ days to record clutch size, chick age after hatching and brood size, and to track the number of chicks and record their approximate fledging date. This allowed us to back-calculate hatch dates (with hatch date $=$ day 1 of chick life) and nest initiation dates, based on the chick age and a 15-day incubation period, respectively. When approaching nests, efforts were made not to leave obvious tracks that could lead predators to the nest and therefore artificially lower breeding success. Once a nest was found empty, or with cold eggs or dead chicks, it was considered no longer active. All information was then collected to establish whether the chicks had successfully fledged or died before fledging. If the chicks had died prior to fledging the most likely reason for nest failure was determined. Nests found empty around the estimated fledging 
date which were dry and intact were considered to have successfully fledged. If a nest was found to be damaged, or intact but empty long before the estimated fledging date (more than three days earlier), it was considered predated. If dead chicks or cold eggs were found, the nest was considered abandoned. If cold eggs or dead chicks were found in a wet nest, the nest was considered flooded. We refer to the nests found during the first breeding peak as 'first broods' (before 26 May in 2010, before 2 June in 2011 and before 30 May in 2012) and to those found during the second breeding peak as 'second broods' (after 2 June in 2010, after 10 June in 2011 and after 7 June in 2012). The distinction between first and second broods was made on the basis of the number of nest initiations on a given date. In each year, there was a conspicuous gap of 9-10 days during which no nests were initiated, and we classified all nests that were initiated before the nest initiation gap as 'first broods' and all nests initiated after the gap as 'second broods'. Nests were also found outside study plots (up to c. $400 \mathrm{~m}$ from plot boundary), but these nests were only considered for the analysis of nest survival and fledgling number per nest.

In 2010 we carried out a pilot study to test the fieldwork requirements and search effort was likely insufficient to detect all nests in a given plot. In 2011 and 2012 we attempted to find all nests within a plot.

\section{Singing male surveys}

To assess whether the number of singing males was correlated with area productivity and nest density, we performed 2-3 surveys of singing males on each plot between 18 May and 6 June (first broods) and between 26 June and 8 July (second broods). Each survey started 30 minutes prior to sunset, at the period of the highest male singing activity (Dyrcz and Zdunek 1993a). Surveys were not attempted in windy or rainy weather. A survey on a given plot was simultaneously conducted by $2-3$ persons, walking in a straight line $100 \mathrm{~m}$ apart. The observers walked along the plot at a speed of c.10o $\mathrm{m}$ in four minutes and recorded all vocalising males. The number and distribution of singing males from a given survey were then compared between observers to exclude birds being counted twice and individuals singing outside the plot. The direction of the survey was alternated between surveys in a given brood. We used the mean number of males between the surveys in a given brood for analysis rather than the maximum number, in order to avoid overestimation of male density due to movement of males in and out of plot.

\section{Statistical analysis}

\section{Effects of mowing on area productivity, nest density, fledged brood size and male density}

We tested the effect of mowing on area productivity (number of fledglings per hectare), nest density (number of nests per hectare), fledged brood size per successful nest and the density of singing males (number of males per hectare) by classifying the four different successional stages (mown +1 year, mown +2 years, mown +3 years and unmown) as a factor with four levels (hereafter referred to as 'treatment'). We used an information-theoretic approach for inference, by constructing five competing and biologically plausible models for each question and evaluating support for each model using $\mathrm{AIC}_{c}$ (Burnham and Anderson 2002). These five models considered (1) constant response variable; (2) response variable varying by treatment; (3) response variable varying by breeding peak; (4) response variable varying by treatment and breeding peak (treatment + breeding peak), and (5) effects of treatment varying between the first and the second breeding peak (treatment $\times$ breeding peak). The latter three models were necessary because vegetation height and water levels change over the season, which may cause the effects of treatment to differ between the first and the second breeding peak.

We used generalised linear mixed models to assess the effect of treatment while accounting for non-independence of treatment units within the same study plot or area by including 'block' as a 
random intercept in each model (Ten Have et al. 2002, Gillies et al. 2006, Bolker et al. 2009). We fitted all models using the Laplace approximation in R 2.13.I (R Development Core Team 2010) with the package ' lme 4 ', using the following generic formula: lmer(response explanatory variables+(I|plot)). The respective response variables for our four questions were (I) area productivity; (2) nest density; (3) fledgling number per successful nest; and (4) singing male density. The explanatory variables were treatment, breeding peak or the interaction between them, as described above. In the analyses of nest density and area productivity we did not include nests found in 2010, as data collected in the 2010 pilot season did not allow estimation of nest density.

\section{Analysis of nest survival}

In order to assess whether mowing and other environmental variables influenced nest survival, we estimated daily nest survival probabilities. To increase the robustness of these estimates, we used all nests found during our study, both within and outside study plots, in all study years (2010-2012). We used program MARK (White and Burnham 1999), interfaced with R 2.13.1 via the 'RMark' library (Laake and Rexstad 2008), to evaluate biologically plausible scenarios explaining variation in daily nest survival (Dinsmore et al. 2002). These models allowed us to test whether there was support for an effect of mowing on daily nest survival probabilities, while taking temporal variation and other environmental factors into account.

We first constructed six models examining different temporal variation in daily nest survival probabilities, and then used the most parsimonious temporal model structure as a basis for further models examining the influence of environmental variables. We considered the following six temporal model structures, which all included a factor to allow daily nest survival to vary between years: (I) constant daily nest survival throughout the breeding season, (2) a linear temporal trend over the breeding season, (3) a linear temporal trend and variation with the age of a nest (4) a quadratic temporal trend and variation with the age of a nest, (5) a linear temporal trend, variation with the age of a nest, and different survival between the first and the second breeding peak, (6) a linear temporal trend, variation with the age of a nest, and different survival between egg and chick stage.

Prior to the second step, we tested whether environmental variables were correlated, and we did not include highly correlated (Spearman $r_{s}>0.6$ ) variables in the same model (Zuur et al. 2010). We then constructed seven candidate models representing different biological hypotheses to explain variation in Aquatic Warbler nest survival. Specifically, we tested whether nest survival varied among units in different mowing stages (mowing model), with vegetation height (vegetation model), with litter thickness (litter model), or with water depth (water model). Aquatic Warblers nest near the ground, and a high litter layer may affect a nest's vulnerability to flooding (Dyrcz and Zdunek 1993a, Vergeichik and Kozulin 2006b). We therefore included three models which considered that the effect of water would vary with litter thickness measured at the nest site (water $\times$ litter model), that the effect of water would vary among mowing stages, which can have different vegetation structure due to mowing and removal of cut vegetation (water $x$ mowing model), and that the effect of water would vary between the first and the second breeding peak (water $\times$ brood model) to account for fluctuating water levels over the course of a breeding season.

We report the support for each of those models in terms of evidence ratio and the Akaike weight, $\mathrm{AAIC}_{c}$ (Burnham and Anderson 2002) and present parameter estimates for environmental variables from the most parsimonious model. We present model-averaged nest survival with $95 \%$ confidence intervals for our sample of nests.

\section{Effectiveness of male density as an indicator of habitat quality}

We tested whether singing male density could be used as an effective indicator of habitat quality by using a linear regression to test whether male density and area productivity or nest density 
were positively correlated. For this analysis, we used the data from both breeding peaks in 2011 and 2012 as independent samples because both the number of males and the number of nests varied between the two breeding peaks in each treatment type. We did not include data collected in the 2010 pilot season, because these data were not suitable to estimate nest density and productivity.

\section{Historical changes in Aquatic Warbler nest survival and fledged brood size}

Aquatic Warblers were intensively studied in our study area between 1988 and 1991 (Dyrcz and Zdunek 1993a, 1993b), and the present study allowed us to compare fledged brood size of successful nests and nest survival probability to assess whether these productivity components have changed over the past 20 years.

We used the raw monitoring data from 1988-1991 in combination with the data from the present study, and evaluated the support for a 'decade' effect on fledged brood size. We compared three general linear models that assumed that fledged brood size was either constant, varied between years, or varied between the two study periods (1988-1991 and 2010-2012). Nest survival was analysed with the same approach as described above, with candidate models exploring the effect of decade, year, and constant nest survival over time.

\section{Results}

We found 56 Aquatic Warbler nests in 2010 (of which 36 nests were outside plots), 156 nests in 2011 (20 outside) and 152 nests in 2012 (37 outside). Of the 364 nests, 91 (25\%) suffered complete mortality ( $38 \%$ in 2010: $n=21 ; 35 \%$ in 2011; $n=55:$ and $10 \%$ in 2012: $n=15$ ). Nest failure occurred due to flooding ( $14 \%$ of failed nests in 2010 and $67 \%$ of failed nests in 2011; no nests were flooded in 2012), predation (86\% in 2010, $24 \%$ in 2011 and $80 \%$ in 2012) or abandonment (9\% in 2011 and $13 \%$ in 2012). The first laying date was 8 May in 2010, 17 May in 2011 and 9 May in 2012. The last laying date was 17 July in 2010, 8 August in 2011 and 26 July in 2012; the latest observed laying date of a successfully fledged nest was 5 August 2011.

\section{Effect of mowing on area productivity}

The mean productivity across all treatment units was 1.7 fledglings/ha (range 0-4.9). There was very strong support for productivity to vary among mowing treatment units (cumulative $\omega \mathrm{AIC}_{c}=0.98 ;$ Table 1 ), and the most parsimonious model also included an additional effect of breeding peak, suggesting that productivity was higher during the second brood (effect size $=0.53$, $95 \%$ CI 0.11-0.94). Mown +2 years and mown +3 years areas showed much higher productivity per ha than mown +1year areas did, but area productivity appeared to decline slightly after the second year after mowing (Figure $1 \mathrm{~A}$ ).

Table 1. Model selection table evaluating the effect of mowing (treatment) on area productivity, i.e. the number of Aquatic Warbler fledglings produced per ha in a given brood. $k=$ number of estimable parameters, $\mathrm{AIC}_{c}=$ Akaike's information criterion, $\Delta \mathrm{AIC}_{c}=$ difference in $\mathrm{AIC}_{c}$ units to the most parsimonious model, $\omega \mathrm{AIC}_{c}=$ relative weight of evidence for each model.

\begin{tabular}{lrrrlll}
\hline & \multicolumn{1}{c}{$k$} & $\mathrm{AIC}_{c}$ & $\Delta \mathrm{AIC}_{c}$ & Evidence ratio & $\mathrm{NAIC}_{c}$ & Deviance \\
\hline brood + treatment & 7 & 123.01 & 0.00 & 1.00 & 0.70 & 106.06 \\
treatment & 6 & 124.81 & 1.81 & 0.41 & 0.28 & 110.66 \\
brood $\times$ treatment & 10 & 129.85 & 6.85 & 0.03 & 0.02 & 103.57 \\
null & 3 & 145.15 & 22.14 & 0.00 & 0.00 & 138.57 \\
brood & 4 & 145.25 & 22.25 & 0.00 & 0.00 & 136.28 \\
\hline
\end{tabular}



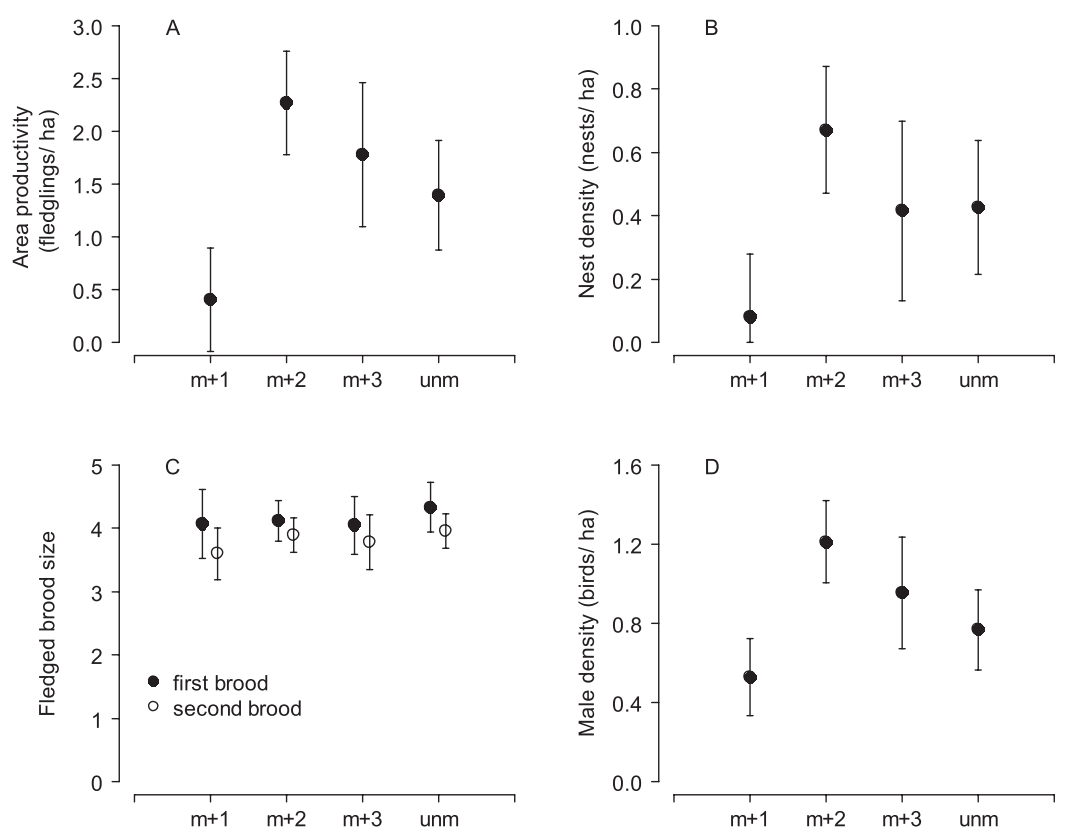

Time since mowing

Figure 1. Effects of mowing on (A) number of fledglings per area (area productivity), (B) nest density, (C) fledged brood size of successful nests, and (D) density of singing males of Aquatic Warblers in the Biebrza Valley, Poland. The four categories reflect areas that were mown in the autumn and/or winter just prior to the current breeding season $(\mathrm{m}+1)$; mown in the autumn and/or winter one year before the current breeding season $(\mathrm{m}+2)$; mown in the autumn and/or winter two years before the current breeding season $(\mathrm{m}+3)$; and not mown for at least 1o years (unm). Means $\pm 95 \%$ confidence intervals estimated from the most parsimonious model are shown.

\section{Effect of mowing on nest density}

The average cumulative nest density across broods and plots was 0.6 nests/ha (range o-1.8). The model considering that nest density varied between both mowing treatment and the two breeding peaks received very high support from the data $\left(\omega \mathrm{AIC}_{c}=0.89\right.$; Table 2$)$. There was very little support for nest density varying only with mowing treatment $\left(\omega \mathrm{AIC} C_{c}=0.02\right)$ or for the effect of treatment to vary between the two breeding peaks $\left(\omega \mathrm{AIC}_{c}=0.00\right)$. Nest density was highest in mown +2 years areas and lowest in mown +1 year areas (Figure 1 B). Nest density was higher in the second breeding peak relative to the first breeding peak (effect size $=0.38,95 \% \mathrm{CI} 0.2 \mathrm{O}-0.55$ ).

Table 2. Model selection table evaluating the effect of mowing (treatment) on the density of Aquatic Warbler

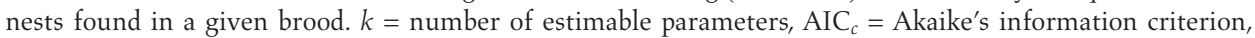
$\Delta \mathrm{AIC}_{c}=$ difference in $\mathrm{AIC}_{c}$ units to the most parsimonious model, $\omega \mathrm{AIC}_{c}=$ relative weight of evidence for each model.

\begin{tabular}{lcccccc}
\hline & $k$ & $\mathrm{AIC}_{c}$ & $\Delta \mathrm{AIC}_{c}$ & Evidence ratio & $\omega \mathrm{AIC}_{c}$ & Deviance \\
\hline brood + treatment & 7 & 53.23 & 0.00 & 1.00 & 0.89 & 36.28 \\
brood & 4 & 58.03 & 4.80 & 0.09 & 0.08 & 49.05 \\
treatment & 6 & 61.12 & 7.89 & 0.02 & 0.02 & 46.96 \\
null & 3 & 62.72 & 9.49 & 0.01 & 0.01 & 56.15 \\
brood $\times$ treatment & 10 & 63.85 & 10.63 & 0.00 & 0.00 & 37.57 \\
\hline
\end{tabular}


Table 3. Model selection summary of 13 candidate models explaining variation in Aquatic Warbler nest survival in the Biebrza National Park, Poland, in 2010-2012. See text for description and justification for each model. $k=$ number of estimable parameters, $\mathrm{AIC}_{c}=$ Akaike's information criterion, $\Delta \mathrm{AIC}_{c}=$ difference in $\mathrm{AIC}_{c}$ units to the most parsimonious model, $\omega \mathrm{AIC}_{c}=$ relative weight of evidence for each model.

\begin{tabular}{lrrrrr}
\hline Model & $k$ & $\mathrm{AIC}_{\mathrm{c}}$ & $\Delta \mathrm{AIC}_{\mathrm{c}}$ & $\omega \mathrm{AIC}_{\mathrm{c}}$ & Deviance \\
\hline time + year + nest age & 5 & 568.24 & 0.00 & 0.26 & 558.22 \\
time + year + brood + nest age & 6 & 569.07 & 0.82 & 0.17 & 557.04 \\
time + year + vegetation height + nest age & 6 & 569.93 & 1.69 & 0.11 & 557.91 \\
time + year + litter depth $\times$ water depth + nest age & 8 & 570.00 & 1.76 & 0.11 & 553.96 \\
time + year + litter depth + nest age & 6 & 570.15 & 1.91 & 0.10 & 558.12 \\
time + year + water depth + nest age & 6 & 570.18 & 1.94 & 0.10 & 558.15 \\
time + year + stage + nest age & 6 & 570.25 & 2.01 & 0.09 & 558.22 \\
time + year + brood $\times$ water depth + nest age & 8 & 572.28 & 4.04 & 0.03 & 556.24 \\
time + year + mowing + nest age & 8 & 574.08 & 5.84 & 0.01 & 558.03 \\
time + year + mowing $\times$ water depth + nest age & 12 & 576.39 & 8.15 & 0.00 & 552.30 \\
year & 3 & 576.43 & 8.19 & 0.00 & 570.42 \\
time + year & 4 & 576.78 & 8.54 & 0.00 & 568.77 \\
time ${ }^{2}+$ year + nest age & 5 & 578.47 & 10.23 & 0.00 & 568.45 \\
\hline
\end{tabular}

\section{Effect of mowing on nest survival}

The most supported temporal structure in our daily nest survival models considered a generally declining daily nest survival probability over the breeding season, and a decreasing nest survival probability with increasing age of the nest (Table 3 ). Because nest survival varied strongly between years, the temporal model structure of our most parsimonious model explained most of the variation in the data set, and there was considerable model selection uncertainty for additional environmental variables. There was some evidence that nest survival was higher for the first breeding peak $\left(b=1.11 \pm 0.96 ; \omega \mathrm{AIC}_{c}=0.17\right)$, but less and equivocal support for the influence of vegetation height $\left(b=0.49 \pm 0.45 ; \omega \mathrm{AIC}_{c}=0.11\right)$, water depth $(b=0.008 \pm 0.03$; $\left.\omega \mathrm{AIC}_{c}=0.10\right)$, and thickness of the litter layer $\left(b=-0.004 \pm 0.01 ; \omega \mathrm{AIC}_{c}=0.10\right)$, or for the water by litter interaction effect $\left(\omega \mathrm{AIC}_{c}=\right.$ o.II, Table 3$)$. There was no support for any model considering that nest survival varied among areas in different temporal stages after mowing (Table 3 ).

\section{Effect of mowing on fledged brood size}

Fledged brood size per successful nest (Figure ${ }_{1 C}$ ) was on average 4.0 (95\% CI 3.8-4.I), and ranged from one to six fledglings. The model with the brood effect $\left(\omega \mathrm{AIC}_{c}=0.64\right)$ and the null model $\left(\omega \mathrm{AIC}_{c}=0.35\right)$ received the highest support from the data. Models considering that fledged brood size varied with treatment received virtually no support (Table 4 ).

Table 4. Model selection table evaluating the effect of mowing (treatment) on the number of fledglings per

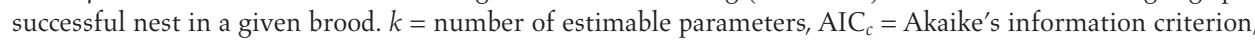
$\Delta \mathrm{AIC}_{c}=$ difference in $\mathrm{AIC}_{c}$ units to the most parsimonious model, $\omega \mathrm{AIC}_{c}=$ relative weight of evidence for each model.

\begin{tabular}{lcccccc}
\hline & $k$ & $\mathrm{AIC}_{c}$ & $\Delta \mathrm{AIC}_{c}$ & Evidence ratio & $\omega_{\mathrm{AIC}}$ & Deviance \\
\hline brood & 4 & 788.97 & 0.00 & 1.00 & 0.64 & 780.81 \\
null & 3 & 790.16 & 1.20 & 0.55 & 0.35 & 784.07 \\
brood + treatment & 7 & 797.76 & 8.80 & 0.01 & 0.01 & 783.33 \\
treatment & 6 & 798.87 & 9.91 & 0.01 & 0.00 & 786.55 \\
brood $\times$ treatment & 10 & 804.48 & 15.52 & 0.00 & 0.00 & 783.62 \\
\hline
\end{tabular}


Table 5. Model selection table evaluating the effect of mowing (treatment) on density of Aquatic Warbler males based on 23 surveys in each management unit during each brood. $k=$ number of estimable parameters, $\mathrm{AIC}_{c}=$ Akaike's information criterion, $\Delta \mathrm{AIC}_{c}=$ difference in $\mathrm{AIC}_{c}$ units to the most parsimonious model, $\omega \mathrm{AIC}_{c}=$ relative weight of evidence for each model.

\begin{tabular}{lrrrlll}
\hline & \multicolumn{1}{c}{$k$} & $\mathrm{AIC}_{c}$ & $\Delta \mathrm{AIC}_{c}$ & Evidence ratio & $\omega \mathrm{AIC}_{c}$ & Deviance \\
\hline brood + treatment & 7 & 54.41 & 0.00 & 1.00 & 0.85 & 37.98 \\
brood $\times$ treatment & 10 & 58.74 & 4.33 & 0.12 & 0.10 & 33.62 \\
treatment & 6 & 60.01 & 5.60 & 0.06 & 0.05 & 46.23 \\
brood & 4 & 71.39 & 16.97 & 0.00 & 0.00 & 62.57 \\
null & 3 & 73.12 & 18.70 & 0.00 & 0.00 & 66.64 \\
\hline
\end{tabular}

\section{Effect of mowing on density of singing males}

The model considering different male densities among different mowing treatment units and breeding peaks received the most support from the data $\left(\omega \mathrm{AIC}_{c}=0.85 ;\right.$ Table 5$)$. There was little support for the effect of mowing to differ between mowing treatments only $\left(\omega \mathrm{AIC}_{c}=0.05\right)$, or for the effect of mowing to vary between breeding peaks $\left(\omega \mathrm{AIC}_{c}=0.10\right.$, Table 5$)$. Male density was more than twice as high in mown +2 years areas than in mown +1 year areas; male density also appeared to gradually decrease after 2 years after mowing (Figure $1 \mathrm{D}$ ).

\section{Is singing male density correlated with productivity of an area?}

Density of singing males was higher in areas with higher area productivity $(b=1.40 \pm 0.29$, $P<0.001, r^{2}=0.33$; Figure $\left.3 \mathrm{~A}\right)$ and higher nest density $\left(b=0.59 \pm 0.11, P<0.001, r^{2}=0.37\right.$; Figure $\left.{ }_{3} \mathrm{~B}\right)$.
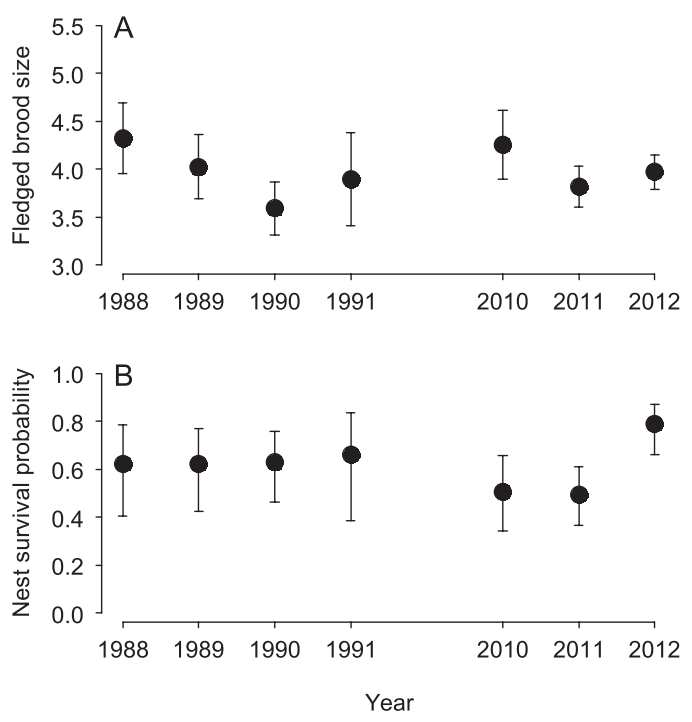

Figure 2. Comparison of (A) fledged brood size of successful nests and (B) nest survival probability of Aquatic Warblers the in Biebrza Valley, Poland, between historic (1988-1991) and current (2010-2012) period. Means $\pm 95 \%$ confidence intervals estimated from the most parsimonious models are shown. There was no evidence for a systematic decline in fledged brood size or nest survival between these two periods. 

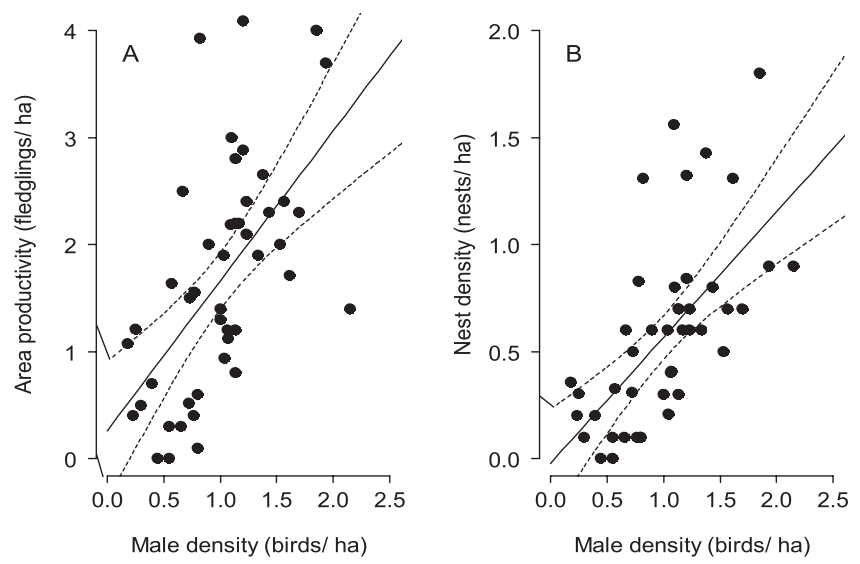

Figure 3. Positive relationship between (A) Aquatic Warbler productivity in an area and the density of singing males, and (B) Aquatic Warbler nest density and the density of singing males. Lines indicate linear regression fit and $95 \%$ confidence intervals.

\section{Historical changes in nest survival and fledged brood size}

The model-averaged predicted nest survival probability was 0.62 (95\% CI $0.48-0.73$ ) over the three years of our study. However, nest survival varied substantially between years, ranging from 0.49 (95\% CI 0.36-0.61) in 2011 to 0.79 (95\% CI o.66-0.87) in 2012. Due to this large interannual variation in nest survival there was no support for a model that considered a decadal effect on nest survival $\left(\omega \mathrm{AIC}_{c}=\right.$ o.001) when we used our data in conjunction with the data collected in the same area in 1988-1991 to test whether nest survival had changed systematically over the past two decades (Figure 2 B). Nest survival estimated for 1988-1991 was on average 0.63 (95\% CI: $0.43-0.78$ ), and thus almost identical to the mean nest survival estimated for the period 2010-2012; however, inter-annual variation was less pronounced over the 1988-1991 period (Figure 2B). Fledged brood size did not vary between 1988-1991 and 2010-2012, but varied substantially between years (year model, $\omega \mathrm{AIC} c=0.79$; decade model, $\omega \mathrm{AIC}_{c}=0.06$; Figure 2A).

\section{Discussion}

In areas with advanced overgrowth and bush encroachment, habitat management via mowing can increase habitat quality for the Aquatic Warbler (Kloskowski and Krogulec 1999, Tanneberger et al. 2010). However, mowing induces a short-term decrease in habitat suitability, as the studied areas had the lowest productivity per unit area in the first year after they had been mown (Figure IA). With time and natural regeneration of vegetation, habitat quality improves rapidly and productivity peaks after two years. We found a gradual decrease in area productivity after more than two years (Figure IA), but productivity did not decline to levels observed in the first year after mowing. Hence, our results suggest that mowing in mesotrophic sedge fen-mires should be performed less frequently than every two years. Current agri-environmental schemes in Poland stipulate that farmers mow Aquatic Warbler habitats every two years, and we recommend changing this legislation to avoid potential mismanagement. In addition, mowing only subsections of the breeding area in a given year would ensure the annual availability of high quality habitat, and we recommend that mowing is performed in a shifting rotation where only parts of the breeding area are mown in a given year.

Of the three components of area productivity that we studied, only nest density was affected by mowing, reaching the highest density in the second year after mowing (Figure $1 B$ ). By 
contrast, nest survival and fledged brood size of successful nests were similar across all mowing treatments and thus did not appear to vary with succession (Figure ${ }_{1} \mathrm{C}$, Table 3 ). Therefore, the increase in productivity of an area two years after mowing is a result of higher nest densities. This suggests that the effect of mowing on area productivity in the Aquatic Warbler is mediated by active nest site selection by females, which avoid areas in the first year after mowing and select areas with taller vegetation and a thicker litter layer (Dyrcz and Zdunek 1993a, Tanneberger et al. 2010). This habitat selection leads to a higher nest density and ultimately a higher number of fledglings produced per unit area in the second and third year after mowing when vegetation and litter layer have recovered.

In contrast to nest density, neither nest survival nor fledged brood size differed among treatment units. Nest survival, an important determinant of seasonal fecundity in ground-nesting species (Mattsson and Cooper 2007, Etterson et al. 2011), was best explained by year-to-year variation and intra-seasonal temporal variables in our study (Table 3). Environmental variables such as vegetation, litter layer and water depth did not appear to have a consistently important effect on nest survival in all years. For example, one of our study years (2011) experienced very high rainfall and very high water levels in July, leading to high levels of nest failure due to flooding, a known risk for Aquatic Warblers (Kozulin et al. 2004, Vergeichik and Kozulin 2006a). This effect was virtually absent in 2012, resulting in annually varying importance of environmental variables on nest survival that may to some extent explain annual variations in fecundity.

We did not detect long-term changes in two components of Aquatic Warbler productivity, nest survival and fledged brood size of successful nests. However, our data indicate considerable inter-annual variation in nest survival, which appeared to be higher in recent years (our study) than twenty years ago (Figure 2). A potential explanation for this high variability is the large amount of rainfall and nest flooding in July 2011, which may reflect effects of climate change towards a higher frequency of extreme events (IPCC 2007). Extreme weather events may include heavy rainstorms, such as the events in 2011 that caused many nest failures in our study, or prolonged drought, which could lead to greater accessibility of otherwise wet marshes to terrestrial predators; predation by ground predators is another important factor accounting for nest losses of Aquatic Warblers (Dyrcz and Zdunek 1993b). Increased climatic variability has affected nest survival in other ground-nesting birds (Albright et al. 2010, Dreitz et al. 2012). The Aquatic Warbler is well-adapted to annually fluctuating environmental conditions (Vergeichik and Kozulin 2006a, b), but increasing occurrence of extreme weather events combined with habitat loss or unfavourable conditions at wintering sites (Flade et al. 2011) may contribute to population declines. However, longer time series of productivity data would be necessary to assess the effect of climatic variability on the annual fecundity and population dynamics of Aquatic Warblers.

We found that density of singing males was positively correlated with nest density and area productivity (Figure 3). This crucial finding shows that singing male surveys can be used as indicators for the current local reproductive output, which is important because counting singing males is far less invasive and time-consuming than direct estimation of nest density and productivity. Our result is consistent with earlier research, which suggested that males generally follow the distribution of fertile females (Schulze-Hagen et al. 1999). In addition, the effect of mowing on male density mirrored the effect of mowing on area productivity: male density was the lowest in the first year after mowing, reached the highest values two years after mowing and appeared to decline afterwards (Figure $\mathrm{ID}$ ). Therefore, the fitness effects of mowing management can be accurately monitored by counting singing males.

Throughout our study the latest clutch initiation dates were between the end of July and beginning of August. The last fledglings would therefore reach independence as late as September. While the timing of nest initiation can be very flexible in response to water table fluctuations (Vergeichik and Kozulin 2006b), earlier studies did not report successful nests at such late stages of the breeding season (Dyrcz and Zdunek 1993a). To avoid affecting possible 
late broods through the initiation of mowing, we recommend starting mowing not before mid-September.

In conclusion, our study has provided extensive evidence that mowing is an essential tool of habitat management for the Aquatic Warbler, which ensures high productivity by this globally threatened species. The optimal mowing frequency in mesotrophic sedge fen mires appears to be less than every two years, and because mowing induces a short-term negative effect on area productivity, we advise against mowing all of the breeding area in a given year. The fitness consequences of mowing can be monitored by counting singing males, as this simple metric was positively correlated with important demographic parameters. Importantly, we showed that components of Aquatic Warbler productivity have remained unchanged over the past two decades. The high inter-annual variation in nest survival calls for long-term studies to find underlying mechanisms and assess whether global climate change will add to the challenges the Aquatic Warbler faces on its breeding grounds.

\section{Acknowledgements}

We greatly appreciate assistance of many field volunteers and the Director of the Biebrza National Park, who granted access to the Park and allowed us to conduct the study. We also thank Piotr Marczakiewicz for his help in selection and set-up of study plots. Funding was provided by projects LIFEo5 NAT/PL/OooIOI and LIFEog NAT/PL/ooo26o which were carried out by OTOP (the Polish Society for the Protection of Birds).

\section{References}

Albright, T. P., Pidgeon, A. M., Rittenhouse, C. D., Clayton, M. K., Wardlow, B. D., Flather, C. H., Culbert, P. D. and Radeloff, V. C. (2010) Combined effects of heat waves and droughts on avian communities across the conterminous United States. Ecosphere 1.

Aquatic Warbler Conservation Team (1999) World population, trends and conservation status of the Aquatic Warbler Acrocephalus paludicola. Vogelwelt 120: 65-85.

BirdLife International (2012) Species factsheet: Acrocephalus paludicola. Available at: http:// www.birdlife.org/datazone/speciesfactsheet. php?id=7597

Bolker, B. M., Brooks, M. E., Clark, C. J., Geange, S. W., Poulsen, J. R., Stevens, M. H. H. and White, J.-S. S. (2009) Generalized linear mixed models: a practical guide for ecology and evolution. Trends Ecol. Evol. 24: 127-135.

Burnham, K. P. and Anderson, D. R. (2002) Model selection and multimodel inference. A practical information-theoretic approach, 2nd edition ed. New York: Springer.

Dinsmore, S. J., White, G. C. and Knopf, F. L. (2002) Advanced techniques for modeling avian nest survival. Ecology 83: 3476-3488.
Dreitz, V. J., Conrey, R. Y. and Skagen, S. K. (2012) Drought and cooler temperatures are associated with higher nest survival in Mountain Plovers. Avian Conserv. Ecol. 7: 6.

Dyrcz, A. and Zdunek, W. (1993a) Breeding ecology of the Aquatic Warbler Acrocephalus paludicola on the Biebrza marshes, northeast Poland. Ibis 135: 181-189.

Dyrcz, A. and Zdunek, W. (1993b) Breeding statistics of the Aquatic Warbler Acrocephalus paludicola on the Biebrza marshes, northeast Poland. J. Orn. 134: 317-323.

Etterson, M. A., Ellis-Felege, S. N., Evers, D., Gauthier, G., Grzybowski, J. A., Mattsson, B. J., Nagy, L. R., Olsen, B. J., Pease, C. M., van der Burg, M. P. and Potvien, A. (2011) Modeling fecundity in birds: Conceptual overview, current models, and considerations for future developments. Ecol. Model. 222: 2178-2190.

Flade, M., Diop, I., Haase, M., Le Nevé, A., Oppel, S., Tegetmeyer, C., Vogel, A. and Salewski, V. (2011) Distribution, ecology and threat status of the Aquatic Warblers Acrocephalus paludicola in West Africa. J. Orn. 152: $\mathrm{S}_{129}-\mathrm{S}_{140 .}$

Flade, M. and Lachmann, L. (2008) International species action plan for the 
Aquatic Warbler Acrocephalus paludicola. Cambridge, UK: BirdLife International.

Gillies, C. S., Hebblewhite, M., Nielsen, S. E., Krawchuk, M. A., Aldridge, C. L., Frair, J. L., Saher, D. J., Stevens, C. E. and Jerde, C. L. (2006) Application of random effects to the study of resource selection by animals. J. Anim. Ecol. 75: 887-898.

IPCC (2007) Summary for policymakers. in Solomon, S., Qin, D., Manning, M., Chen, Z., Marquis, M., Averyt, K. B., Tignor, M. and Miller, H. L., eds. Climate change 2007: The physical science basis. Contribution of working group I to the fourth assessment report of the Intergovernmental Panel on Climate Change: Cambridge, UK: Cambridge University Press.

Kloskowski, J. and Krogulec, J. (1999) Habitat selection of Aquatic Warbler Acrocephalus paludicola in Poland: consequences for conservation of the breeding areas. Vogelwelt 120: 113-120.

Kozulin, A. and Flade, M. (1999) Breeding habitat, abundance and conservation status of the Aquatic Warbler Acrocephalus paludicola in Belarus. Vogelwelt 120: 97-112.

Kozulin, A., Vergeichik, L. and Stepanovich, Y. (2004) Factors affecting fluctuations of the Aquatic Warbler Acrocephalus paludicola population of Belarussian mires. Acta Ornithol. 39: 35-44.

Laake, J. L. and Rexstad, E. A. (2008) RMark - an alternative approach to building linear models in MARK. Available at: http://www.phidot. org/software/mark/docs/book/pdf/app_3.pdf

Mattsson, B. J. and Cooper, R. J. (2007) Which life-history components determine breeding productivity for individual songbirds? A case study of the Louisiana Waterthrush (Seiurus motacilla). Auk 124: 1186-1200.

$\mathrm{R}$ Development Core Team (2010) R: A language and environment for statistical computing. Available at: http://www.R-project.org/. Vienna, Austria: R Foundation for Statistical Computing.

Schulze-Hagen, K. (1991) Acrocephalus paludicola (Vieillot 1817)-Seggenrohrsänger. in Glutz von Blotzheim, U. N., ed. Handbuch der Vögel Mitteleuropas: Wiesbaden: Aula.
Schulze-Hagen, K., Leisler, B., Schäfer, H. M. and Schmidt, V. (1999) The breeding system of the Aquatic Warbler Acrocephalus paludicola - a review of new results. Vogelwelt 120: 87-96.

Tanneberger, F., Bellebaum, J., Fartmann, T., Haferland, H.-J., Helmecke, A., Jehle, P., Just, P. and Sadlik, J. (2008) Rapid deterioration of Aquatic Warbler Acrocephalus paludicola habitats at the western margin of the breeding range. J. Orn. 149: 105-115.

Tanneberger, F., Flade, M., Preiksa, Z. and Schröder, B. (2010) Habitat selection of the globally threatened Aquatic Warbler Acrocephalus paludicola at the western margin of its breeding range and implications for management. Ibis 152: 347-358.

Tanneberger, F., Tegetmeyer, C., Dylawerski, M., Flade, M. and Joosten, H. (2009) Commercially cut reed as a new and sustainable habitat for the globally threatened Aquatic Warbler. Biodiv. Conserv. 18: 1475-1489.

Ten Have, T. R., Reboussin, B. A., Miller, M. E. and Kunselman, A. (2002) Mixed effects logistic regression models for multiple longitudinal binary functional limitation responses with informative drop-out and confounding by baseline outcomes. Biometrics 58: 137-144.

Vergeichik, L. and Kozulin, A. (2006a) Breeding ecology of Aquatic Warblers Acrocephalus paludicola in their key habitats in SW Belarus. Acta Ornithol. 41: 153-161.

Vergeichik, L. and Kozulin, A. (2006b) Changing nesting dates and nest placement as adaptations of Aquatic Warbler Acrocephalus paludicola to unstable nesting conditions on fen mires in Belarus. Vogelwelt 127: 163.

Wawrzyniak, H. and Sohns, G. (1977) Der Seggenrohrsänger, Acrocephalus paludicola. Wittenberg, Germany: A. Ziemsen.

White, G. C. and Burnham, K. P. (1999) Program MARK: survival estimation from populations of marked animals. Bird Study 46: $120-139$.

Zuur, A. F., Ieno, E. N. and Elphick, C. S. (2010) A protocol for data exploration to avoid common statistical problems. Meth. Ecol. Evol. 1: 3-14. 
JUSTYNA KUBACKA*

Jagiellonian University, Institute of Environmental Sciences, Gronostajowa 7, Kraków 30-387, Poland.

\section{STEFFEN OPPEL, LARS LACHMANN}

Royal Society for the Protection of Birds, The Lodge, Sandy, Bedfordshire SG192DL, UK.

ANDRZEJ DYRCZ, WANDA ZDUNEK

Department of Behavioural Ecology, University of Wrocław, Sienkiewicza 21, Wrocław 50-335, Poland.

\section{LARS LACHMANN}

NABU, Bundesgeschäftsstelle, Charitéstraße 3, 10117 Berlin, Germany.

J. PEDRO DUARTE BARROS DA COSTA

Rua do Covelo $146 / 1^{\circ}$ Esq., Porto 4200-238, Portugal.

ULLA KAIL

Schalkgasse 2/12, Vienna 1180, Austria.

${ }^{*}$ Author for correspondence; e-mail: justyna.kubacka@uj.edu.pl

Received 18 April 2012; revision accepted 26 November 2012; Published online 28 March 2013 